\title{
Exploration of Undergraduate Students' Attitudes toward Mathematics in Elementary Algebra Course
}

\author{
Soofia Malik \\ University of Northwestern Ohio, U.S.A
}

This action research paper explores if and how the integration of weekly writing assignments in an Elementary Algebra course affects college students' attitudes toward mathematics. This paper also addresses the main factors that college students believe are responsible for the change in their attitudes toward mathematics due to the integration of weekly writing assignments. The study takes place in a developmental mathematics course in a community college located in the Western United States. The findings suggest the incorporation of weekly writing assignments have the potential to improve college students' negative attitudes toward mathematics. Findings also suggest that college students became independent problem solvers and active learners due to the integration of weekly writing assignments in the Elementary Algebra course. Moreover, it was noted that college students were able to figure out their own mistakes and keep a record of their progress, and thus became more confident in mathematics in general as a result of doing weekly writing in mathematics.

Keywords: action research, attitudes toward mathematics, cognitive conflict, reflective abstraction, writing in mathematics

As a Teaching Assistant in the mathematics department, I have taught several mathematics and statistics courses. In the spring of 2013, I taught two sections of a statistics course. When I presented a solution to a problem in class as an example after introducing a new topic, most of the students seemed to follow me. These students would respond correctly when they were asked about the next step. However, most of these students did not do too well on their tests as they used to do in class. Since I could only spend a day or two at most on a particular topic, I started asking students to do two problems on each topic on their own. I asked students to include in their write up all the steps they took to get to the solution for each assigned problem and this is how I chose communication or writing as means to address my students' needs.

According to the National Council of Teachers of Mathematics (NCTM) Principles and Standards for School Mathematics (2000), 
communication is an essential part of mathematics. It is a process that helps construct meaning. Hirschfeld-Cotton (2008) noted that "when students are challenged to think and reason and then communicate their ideas orally or in writing, true conceptual understanding develops" (p. 4).

"Writing is an effective and practical tool for teaching math problem solving" (Bell \& Bell, 1985, p. 214). Additionally, writing helps build thinking skills for mathematics students as they become accustomed to reflecting and synthesizing as parts of a normal sequence involved in communicating about mathematics (Pugalee, 1997). Some researchers have explored the effects of writing and reflecting on their students' problemsolving skills on conceptual understanding and achievements (Allen, 1991; Bell \& Bell, 1985; Hayden, 1989; Hirschfeld-Cotton, 2008). According to Hirschfeld-Cotton (2008) by encouraging students to express their thinking orally or in writing, we can force students to reflect on their own thinking which can, in turn, lead to achieving better grades in mathematics.

In the spring of 2015 semester, I taught one section of Elementary Algebra at a community college. The course is very self-paced and the goal of the instructor is very limited to checking and recording their weekly grades. There is no lecture and the students have to watch videos in order to understand the concepts. The students then do the homework online and also take their proctored tests online using MyLabsPlus for each module. The course is very traditional in nature and I wanted to incorporate some regular writing activities so that I can understand the students' thought process. The purpose of this study was, therefore, to qualitatively explore whether communicating ideas in writing affects college students' attitudes toward mathematics. Specifically, the goal was to look at the changes, if any, in my students' attitudes toward mathematics due to weekly writing assignments that involved students' reflection. Thus, I proposed to conduct a qualitative exploration of Elementary Algebra students' attitudes toward mathematics due to weekly writing assignments. In particular, the following research questions were investigated:

1. Does the integration of weekly writing assignments in the Elementary Algebra course affect college students' attitudes toward mathematics?

2. What are the main factors responsible for college students' positive/negative attitudes toward mathematics due to the integration of weekly writing assignments?

As a teaching assistant in a mathematics department, I had taught several undergraduate level mathematics and statistics courses. I first taught at a Technological university where students were largely male and later at a Liberal Arts university where students were mainly female. However, what was common was that some students due to negative attitudes toward mathematics did not do well and thus end up failing the course. I began to take 
interest in learning about my students' attitudes toward mathematics, most importantly, I wanted to see how I could make a difference by changing their negative attitudes. Unfortunately, most of the literature discussed and mentioned the factors and causes of these negative beliefs and effects (Baloğlu, 2003; Barnes, 2006; Betz, 1978; Daley \& Onwuegbuzie, 1997; Hembree, 1990; Stuart, 2000; Wilson \& Onwuegbuzie, 2001). Instead of looking only at the causes of these negative attitudes that most students develop in their past school experiences, I also chose to focus on the ways in which students' attitudes may be improved. This project certainly helped me in getting answers to these questions.

\section{Literature Review}

Previously math teachers used to rely merely on skill-building and conceptual understanding activities; recently, however, teachers have started to realize that "writing during a math lesson is more than just a way to document information: it is a way to deepen student learning and a tool for helping students gain new perspectives" (Urquhart, 2009, p. 3). According to the National Council of Teachers of Mathematics (NCTM) Principles and Standards for School Mathematics (2000), communication is an essential part of mathematics. Reflection and communication are closely connected processes in mathematics learning. Incorporating both in mathematics courses in the form of writing activities can help students consolidate their thinking (NCTM, 2000). Furthermore, according to the National Institute for Literacy (2007), an increasing number of researchers agree that just like reading skills, improving students' writing skills improves their capacity to learn.

\section{Benefits of Writing in Mathematics}

Hirschfeld-Cotton (2008) pointed out that by encouraging students to express their thinking orally or in writing and by forcing students to reflect on their thinking about mathematics problems can lead to an improvement in their grades in mathematics courses. Moreover, creating opportunities for students to reconstruct their solutions and explain and justify their ideas orally or in writing deepens their understanding. Countryman (1992) explored the relationship between writing and mathematics and offered the following recommendations. She argued that students should write: (1) to keep ongoing records about what they are doing and learning, (2) in order to solve math problems, (3) to explain mathematical ideas, and (4) to describe learning processes. She also recommended six types of writing that teachers may employ in their classrooms: freewriting, biographies, learning logs and journals, summaries, word problems, and formal writing. She believes that through writing, students become active in the classrooms and in the learning process. Countryman stressed the importance of students' participation in the construction of their own learning. She mentioned that collaboration is a basis 
for learning and writing is a tool that can heighten the effects of collaboration. Detailed information about the type(s) of writing assignments is included later in this report.

In a quasi-experimental study, Idris (2009) investigated the effects of using writing activities on students' understanding and achievement in a calculus course. The participants were enrolled in two different secondary schools in Malaysia. Each school was assigned one intact class as an experimental group and another intact class as the control group. The experimental group learned mathematics by using the writing activities for five weeks, while the control group learned mathematics by using traditional whole-class instruction. A highly reliable $(\alpha=0.87)$, 20-item Calculus Achievement test was designed to measure students' achievement in both groups. Students in the experimental group scored significantly higher on the Calculus Achievement test than the control group students. Idris (2009) did not include attitudes toward mathematics in his study.

In a separate quasi-experimental study, Jurdak and Abu Zein (1998) investigated the effect of journal writing on college students' achievement and attitudes toward mathematics. Achievement variables included conceptual understanding, procedural knowledge, problem-solving, mathematics school achievement, and mathematical communication. The journal-writing (JW) group received the same mathematics instruction as the non-journal-writing (NJW) group, except that the JW group engaged in prompted journal writing for 7 to 10 minutes at the end of each class period, three times a week, for 12 weeks. The NJW group engaged in mathematics practice problems during the same period. The results revealed that students in the treatment group found journal writing to have both cognitive and affective benefits. The abovementioned studies did not explore the factors behind their students' achievement nor did they address the factors responsible for their students' positive/negative attitudes toward mathematics.

\section{Attitudes toward Mathematics}

In this study, attitudes toward mathematics have been defined as a positive or negative emotional disposition toward mathematics (Haladyna, Shaughnessy, \& Shaughnessy, 1983; McLeod, 1992; Zan \& Martino, 2007). It has also been defined as the emotion that individuals associate with mathematics (positive or negative) based on his/her beliefs toward mathematics, and by how he/she behaves in dealing with mathematical situations (Hart, 1989; Zan \& Martino, 2007). Several studies have explored the factors associated with attitudes toward mathematics (Ma, 2003; Ma \& $\mathrm{Xu}, 2004)$. For example, $\mathrm{Ma}$ and $\mathrm{Xu}$ (2004) noted that attitudes toward mathematics are responsible for students' achievement scores in mathematics at the secondary school level. Even though the above research includes the factors related to attitudes toward mathematics, research exploring the college 
students' attitudes toward mathematics as a result of writing and reflection on the mathematical activities is limited.

The purpose of this study is to qualitatively explore factors responsible for the positive/negative attitudes toward mathematics of elementary algebra students due to weekly reflection on writing assignments problems for a period of five weeks. The idea of incorporating the writing assignments in this study is influenced by the mechanism, reflection on activity-effect relationships, discussed by Simon, Tzur, Heinz, and Kinzel (2006). They attribute the development of a new conception to a process involving learners' goal-directed activity and natural processes of reflection. The components of the mechanism are as follows: the learners' goal, the activity sequence they employ to try to attain their goal, the result of each attempt (positive or negative), and the effect of each attempt (a conception-based adjustment). Each attempt to reach their goal is preserved as a mental record of experience. I wanted to incorporate this mechanism in my mathematics classroom by having my students keep a mental record of their progress while solving elementary algebra problems that they found challenging. To give them the opportunity to redo the incorrect problems was to give them a chance to make accommodations to their schemas (mental structures) so that they could assimilate the new mathematical concept that created cognitive conflict (or perturbation) to their thought process. In simple words, I gave my students a chance to make revisions to their previously employed strategies that failed to help students reach their goals. Countryman (1992) suggested that students should write in mathematics to keep ongoing records about what they are doing [while solving mathematics problems] so that they become active learners.

Additionally, the course is very self-paced and very traditional in nature meaning that there is minimum teacher involvement. Students are expected to learn and understand the mathematical concepts on their own by watching videos for each section of the Module that they are learning. Most of the students have to rewatch the videos to understand fully the examples included for each Module section. These students certainly need to have learned basic or lower-level mathematical concepts. However, some of the students may not have learned the material well and may not be able to recall and employ the mathematical concepts they need to progress through the course. These students may end up either giving up or may learn incorrect mathematical rules and concepts (Erlwanger, 1973). These students may not know about this and may attribute their failures or incorrect answers to the online tool being too case sensitive. As a teacher, I would only come to know about my students' misconceptions in algebra by having them do some kind of writing. This is the major reason why I incorporated the weekly writing assignments in this course. As mentioned earlier explanation about the writing assignments that were used as an intervention for this study is included later. 
To summarize, I did not expect my students to adapt the entire mechanism reflection on activity-effect relationships based on my feeling that some of the students might not have enough knowledge to reach the goal or solution of the assigned problems. Instead, I asked them to do any type of writing they would like. I suggested they do the writing prompts involving writing steps about the: 1) content, 2) process, or 3) affect. I explained to them in class what each prompt looked like. I explained that the content prompts deal with mathematical concepts and relationships, the process prompts focus on algorithms and problem solving, and effective prompts focus on students' attitudes and feelings while doing mathematics. I assigned students to employ these three types of writing prompts because it has been found that "when students write explanations of their work, teachers can better assess student understanding and progress throughout time" (Urquhart, 2009, p. 7). Writing these kinds of prompts is ideal for formative assessment because they provide teachers with the information; they need to adjust their instruction (Urquhart, 2009).

\section{Implementation}

\section{Setting and Participants}

This study took place at a full-service, coeducational, comprehensive community college with campuses located in two counties in the western state of the US. This research site is accredited by the Higher Learning Commission of the North Central Association of Colleges and Schools. It provides a wide range of academic, career/technical and community education programs. The participants of this qualitative study consisted of community college students, over 18, enrolled in MATH 0920-302 Elementary Algebra course during the spring 2015 semester. I administered a brief survey (see Appendix A). There were seven students enrolled in the course this semester. Out of seven enrolled students, four agreed to participate by filling out the survey and turning in the five writing assignments. All these students were contacted for interviews and each of them was interviewed individually and spent about 30 to 40 minutes in semi-structured, think-aloud interviews.

The course MATH 0920 Elementary Algebra is a three-credit course that consists of Modules 6 to Module 11 of the topics from the textbook "Algebra A Combined Approach by Martin-Gay, $4^{\text {th }}$ Edition." The course has an online component called MyLabsPlus. The students use it to complete their homework assignments and take exams. Every student enrolled in this three-credit course has to attend the one-credit class meeting with their instructor and two additional hours in a math lab anytime during the week to work on module homework or module exams.

\section{Instrumentation and Date Collection}


The modified instrument that I used for this study is Attitudes toward Mathematics Survey (MAT) (see Appendix A), based on a 4-point Likert-type scale. MAT consists of 12 items measuring only one construct - attitudes toward mathematics. All the items are positively worded and possible scores range from 12 to 48; a higher score on MAT reflects a more positive attitude toward mathematics. The MAT survey form includes items such as "I feel comfortable about trying a new problem in mathematics" and "I understand mathematics concepts easily." In addition to survey items, the survey form includes demographic information such as gender and major field of study. All students who completed the survey received participation points. Finally, two open-ended questions were included in the MAT survey requesting students to provide their feelings about watching MATH 0920 videos and to comment about their feelings while solving MATH 0920 problems. The main purpose of these open-ended questions was to determine which students were openly self-reflecting about their attitudes toward mathematics and were willing to share their feelings and experiences. This was also helpful in selecting participants for interviews and in preparing students to self-reflect.

Pre-MAT survey. Before students were introduced to writing assignments (innovation/treatment); they completed the pre-MAT survey. The entire survey administration process took no longer than 5 minutes. Surprisingly, all the students who were present $(n=4)$ on that day filled out the survey. The survey forms were administered to all students on the same day. All students were at different modules due to the self-paced nature of the course as mentioned earlier. The students were given 3 points on their weekly progress record sheet to account for any previously or currently missed class attendance points or lab hours, as an incentive to participate in the study. To be fair, the other three students who were absent on March $6^{\text {th }}$ were also given an opportunity to participate but none of them expressed their willingness, so they were offered a short quiz worth 3 points.

Writing assignments. Soon after students completed the pre-MAT, they were informed about the guidelines of writing assignments. The writing assignments were sent every Saturday or Sunday by email to the students' preferred email address that they provided within the Informed Consent Form starting from March $7^{\text {th }}$ to April $10^{\text {th }}$. There was a total of five writing assignments given during the semester. There were between two and four questions on each writing assignment and students were asked to do all of them individually. The students were asked: (1) to handwrite or type their solutions using MS word, and (2) to reflect on their solutions. Each students' writing assignment was different and consisted of incorrect problems from their current module section (see Appendix C - Examples of Writing Assignments). To be fair, students who chose not to participate were also offered the same writing assignments for extra credit

Submission of writing assignments. The students submitted their writing assignments in person or by email so that if students did not show up 
to class they could still earn points for completing them. There was only one time when a student submitted his writing assignment by email because he was unable to attend the class.

Grading of writing assignments. The assigned problems were graded and the grades were entered manually on MyLabsPlus. The students were also given an opportunity to get points for any of the missed lab hours as a result of submitting the completed assignments. Most of the students had missed their two-hour mandatory lab and found the assignments to be helpful in gaining the missed points.

Post-MAT survey. On April $17^{\text {th }}$, at the end of the treatment, the students completed the post-MAT survey which is the same as the pre-MAT survey. The students received 3 points accounting for any missed lab hour or attendance points. To be fair, students who chose not to complete the survey were offered to complete a short quiz of equal points.

Interviews. The four participants were interviewed one-on-one for 30 minutes approximately. The interviews were semi-structured and each participant was probed to determine if the changes in their attitudes toward mathematics were due to the weekly writing assignments that they turned in, and how (see Appendix B). During the interviews, the participants were also asked to discuss the ways in which the writing assignments changed their attitudes toward mathematics. All the interviews were tape-recorded with the approval of the interviewees. Field notes were also taken during the interviews. A memo documenting my coding experiences will be kept throughout the process of data analysis. The recorded interviews were analyzed using thematic analysis (Patton, 2002).

\section{Findings}

\section{Case 1: Negative-Positive}

Kira is a Multimedia major undergraduate student. She was taking MATH 0920 for the first time. She had completed her Module 6 exam one day before the pre-MAT survey was administered. Her pre-MAT survey score was 21/48 (about 44\%) and she mentioned that her attitude toward mathematics was negative. Also, she had taken 5 attempts to complete her Module 6 Exam. Throughout the five-week innovation period, she had made significant progress through Module 8 . Her pace seemed faster and it took her only three trials to pass Module 7 and Module 8 exams. Her post-MAT survey score was 31/48 (about 65\%) and in response to item \#13, she noted that her attitude toward mathematics was positive. I also compared Kira's responses to the open-ended questions for both the surveys to see if and how they have changed regarding MATH 0920 videos and her feelings while solving problems in MATH 0920. She had opened up more about discussing these questions now than before. For example, on the pre-MAT regarding the MATH 0920 videos, she mentioned: "I like the videos, they have been helping 
with concepts." On the post-MAT, she still maintained that the videos are helpful but she also provided clarification by saying, "I like the videos, because I can watch them whenever and for however long. The videos explain the concepts well and help me understand the math problems." It has also been observed that her attitude about solving mathematics problems have changed. For example, in response to the second open-ended question, earlier in the pre-MAT she had mentioned that sometimes she gets stuck on the problem often because she gets really confused. However, in response to the same question, on the post-MAT, she noted that she is able to finish the problems and better understand them. During the interview, she elaborated by saying that:

I have started liking mathematics more now than before because now I know that I can write my thought process and can figure out where I am wrong. Before, I was not able to figure out the specific part [that was wrong] and was thinking that I was doing the whole problem wrong.

Kira's responses on survey item \#1 (I like Mathematics) and item \# 6 (I feel confident about trying a new problem in Mathematics) both changed from strongly disagree to agree. Her response to the open-ended question regarding solving mathematics problems as well as her interview response confirmed these changes. Additionally, her response on the survey item \#4 (I am motivated in Mathematics) changed from disagree to agree. During the interview, she elaborated that it was due to the fact that before she would redo the entire problem when she would get stuck because of not knowing what she was doing wrong but now due to writing out the entire steps for each problem she has learned a way to address that issue. She now spends less time on mathematics problems than she was spending before and thus she feels motivated in mathematics.

To sum up, the data analysis of survey items, open-ended questions, and interview responses gave rise to the following important findings of Kira. She has started to like Mathematics. Her confidence in trying a new problem in Mathematics has increased. Kira is motivated in Mathematics because she now spends less time in mathematics and score higher than before.

\section{Case 2: Positive-Positive}

Sara. Sara is a Dental Hygiene major undergrad and is taking MATH 0920 for the first time. Sara is the top student in the class and she had just finished her Module 7 exam two days before the pre-MAT survey was administered. Sara's pre-MAT survey score was 35/48 (about 73\%) and in response to item\#13, she mentioned that her attitude toward mathematics was positive. Even though Sara has always shown a positive attitude toward mathematics through her work as well as through her words, it took her four attempts to pass the Module 7 Exam. Throughout the innovation, she 
completed successfully through Module 10 . Her pace seemed to be the same as before but surprisingly she passed her Module 8 exam on a single trial and also it only took her three trials to pass the Module 9 exam. On April $17^{\text {th }}$, she took her post-MAT and her post-MAT survey score came out to be 41/48 (about 85\%). Also, she mentioned that her attitude toward mathematics was positive in response to item\#13.

On the open-ended question regarding solving problems, on both the pre-MAT and post-MAT surveys, Sara mentioned the same points about some problems being harder than others. Her response regarding MATH 0920 videos also was the same for both the pre-MAT and post-MAT in which she pointed out that the examples in the videos are helpful when she gets stuck on a problem. She also feels that the examples in videos are relatively simpler because they walk you through the steps. However, when she is working alone she refers to the examples in videos to see all the steps.

During the interview, in response to the question: do you feel that the incorporation of weekly writing assignments has changed your attitudes toward mathematics. If so, how? She mentioned that she would attribute her positive attitudes toward mathematics to the writing assignments. She added that:

They [the writing assignments]actually helped in a way that when I did not understand those problems and when you gave me the problems that I didn't understand, I could rework through them and figure them out by writing the steps and continuing to do this I seemed to score better on the tests.

Overall, the results have led to an interesting point in the case of Sara. She seems to understand the mathematics better as evident from her responses on survey items \#2 (I understand Mathematics), \#3 (find learning Mathematics easy), and \#9 (I understand Mathematics concepts easily), all changed from disagree to agree. During the interview, she elaborated by saying that:

I think having to write out what you don't understand about the [incorrect] problem helped a lot because then I could figure out what I need to change... it was just that going back and reflecting on it made me understand it better.

Dan. Dan is an Engineering major undergrad and is taking MATH 0920 a second time. He had just finished his Module 7 exam a week before the pre-MAT survey was administered. Dan's pre-MAT survey score was $37 / 48$ (about 77\%) and in response to item\#13, he mentioned that his attitude toward mathematics was positive. Dan is a non-traditional older student and tends to forget lots of material. That is why it took him seven attempts to obtain a passing score on the Module 7 exam. Throughout the innovation, he worked his way up through Module 9 but he had not passed his Module 9 
exam yet. Also, it took him five attempts to pass his Module 8 exam. On April $17^{\text {th }}$, he took his post-MAT and scored 36/48 (about 69\%). His attitude toward mathematics was also marked as positive.

On the open-ended question regarding watching videos for this course, on the pre-MAT survey he mentioned that he liked them and he found them helpful, however, on the post-MAT survey he still maintained that he liked them but also added that "they are kind of boring because it seems that the speaker is just reading a script without showing much enthusiasm." About the pace of the course, he liked being able to do problems and work through them at his own pace, and not having to sit through a lecture.

Interestingly, in the case of Dan, the pre-MAT and post-MAT survey scores are exactly the same indicating that his attitudes toward mathematics have remained constant. Item analysis revealed that each item score is exactly the same as before except for his response in item\#1 (I like Mathematics) changed from strongly agree to agree. During the interview, he clarified that it might be due to the fact that he did not pass his Module 9 exam just yet. From my personal observation, he was writing out the process for most of his problems even before the writing assignments were incorporated, and this might be the reason why he scored the same at different times.

During the interview, Dan mentioned that for him, writing assignments have provided him with the opportunity to go back and fix the incorrect problems in a new way, that is, by writing all the steps to reach the solution. Writing has played a role in helping him learn challenging material and have contributed to his progress in the course. Most importantly, he seeks less assistance from tutors now than before as evident from this quote that is taken from his interview:

I was coming to the lab more often but during the writing assignments I felt that I did not have to come to the lab as much ... they made me think through the problems more and so I did not have to come in for help or do any of that."

\section{Case 3: Negative-Negative}

John is a Dental Hygiene major undergrad and is taking MATH 0920 for the first time. He was and still is, behind all students in the course. He had not started even Module 6 and was just trying to take Module 6 pretest so that he did not have to go through all the homework and exam on module 6 . However, he could not pass his pretest, so he had to do everything required for that module. His pre-MAT survey score was 26/48 (about 54\%) and in response to item\#13, he mentioned that his attitude toward mathematics was negative. Throughout the innovation, he only managed to complete a few sections of Module 6 and had not yet taken the Module 6 exam. He seemed more motivated than before because he was coming to class, but he still did not show a pace that was required of him to progress through the modules. On 
April $17^{\text {th }}$, he took his post-MAT and his score was the same as his pre-MAT survey. Also, he mentioned that his attitude toward mathematics was negative in response to item\#13.

On the open-ended question regarding solving problems, on both surveys, he mentioned that he finds them "difficult to figure out sometimes by myself." His response regarding MATH 0920 videos also was the same for both the pre-MAT and post-MAT in which he pointed out that the examples in the videos seem really easy but when he tries to do a problem on his own he could not figure them out. During the interview, in response to the question: if and how do you feel that the incorporation of weekly writing assignments have changed your attitudes toward mathematics, he mentioned that he would not attribute his negative attitudes toward mathematics due to the writing assignments but it is due to the fact that "I don't really like math. I have always found math to be challenging and difficult. And it only gets harder as you progress."

Since his pre-MAT and post-MAT survey scores were exactly the same 26/48, during the interview I asked about his overall experience about the writing assignments which led to the interesting point that his experience and feelings were mixed as evident from his quote, "Some of them [assigned problems] were difficult and I began to become frustrated, while others were really easy and gave me a boost of confidence moving onto the next problem." Finally, the item analysis of John's survey revealed that he feels more comfortable about trying a new problem in mathematics than before doing the writing assignments.

To summarize, writing assignments seemed to have played a role in improving college students' attitudes toward mathematics. In the case of Kira, her attitude toward mathematics significantly changed from negative to positive. Sara, on the other hand, did score higher on her post-MAT survey than her pre-MAT indicating that her already positive attitude toward mathematics became more positive. Dan's attitude toward mathematics was still positive and his survey scores were almost the same both times. He felt that writing assignments may have a role in his positive attitudes toward mathematics. In the case of John, even though his survey response was negative for both, he did show some motivation by coming to class after the writing assignments were made a part of the course. He also seemed to open up about the issues he was having in this course and the frustrations of solving problems. As mentioned earlier, John was struggling in the course; he knew he would not be able to complete the course and will have to retake it. This may have played a role in his negative attitudes toward mathematics so much so that the confidence that he gained from doing the writing may seem meaningless. 
Most importantly, by comparing the participants' assignments, Kira, Sara, and Dan used the kind of writing prompts that mostly involved process. For example, Dan's solution to a problem involved the following sentence:

In order to solve this problem, I need to find the slope, $\mathrm{m}$, which is the rise over run, and then next find the $b$ which is the y-intercept (a point on the $y$ axis) and then plug in the $m$ and the $b$ values to find the equation of the line.

On the other hand, John's writing prompts were more focused on the effect rather than process. For instance, for one of the problems he wrote,

This problem was a little more difficult but still manageable. When it comes to basic moving of numbers from one side of the $(=)$ sign to the other side, the harder part is what to keep negative and or positive. When I get an answer wrong due to the sign that I did or didn't write down is what frustrates me on certain problems.

Had John focused on writing prompts involving process and content instead of only on the effective prompts, his attitude toward mathematics may have improved. Finally, John seemed to have a lot of misconceptions in mathematics which others did not have. For instance, he treats algebraic expressions and algebraic equations as the same and tries to solve for $\mathrm{x}$ when he sees an algebraic expression. This is the biggest reason why he is behind his classmates and will not be able to pass the course this semester.

Interestingly, all participants, including John, mentioned during the interviews that they would recommend for future students to do the writing in MATH 0920. Finally, all the participants agreed that they would continue to use writing of some kind involving affective or process prompts in their future mathematics course work. John, for example responded by saying that "It [writing in mathematics] provided me with an opportunity to keep track of my feelings [while doing the math]. I may continue to do it in the future." Also, Sara answered this question by saying that "if something was beneficial to me and if someone asked for my opinion [about it], I would certainly say good things [about it]."

\section{The Main Factors}

In response to the research question, what are the main factors responsible for the college students' positive/negative attitudes toward mathematics due to the integration of weekly writing assignments, all participants mentioned ways in which they felt the writing assignments have helped them. For example, Sara felt that writing assignments can be used as study guides and that she will use these assignments as a study guide for Module tests and the comprehensive final exam. She also added that she will continue to do them for harder problems (or those she got incorrect) for the rest of the semester. She also mentioned that by writing all the steps out she 
could seek assistance faster because "in this way, she does not have to explain her thought process verbally to the math tutor." She also added that sometimes she used to get frustrated when the tutors don't understand what she really wanted from them. Sara believes that she understands mathematics concepts promptly now because "she has learned how to break the entire problem into pieces" as a result of doing writing in this course.

Similarly, Kira noted that in her previous mathematics course work she used to spend a lot of time outside of the class because she did not know how to deal with the entire mathematics problem. Now she is able to fully understand what she needs to fix to get to the solution. In short, writing assignments have helped her understand math problems quickly and more fully. She now feels more confident about trying a new problem.

Dan, on the other hand, pointed out that he likes to do things on his own and mentioned that the writing assignments have made him take more responsibility for his learning and have made him an independent problem solver. He elaborated on his comment by saying that "by writing steps on paper for each problem" he is "able to figure out the things on his own" rather than waiting for someone else to be available to assist him. He said he gets back to the written solution at another point if he gets stuck on a problem and sometimes points out his mistakes on his own. Most importantly, because he tends to forget his material, he has discovered that by using more paper-pencil to do the reflection helps him retain the material longer. He mentioned that "it sticks to my brain well and ... it helps me retain more and recall quicker." Similarly, John feels that the writing assignments have provided him with an opportunity to keep track of his feelings while solving difficult math problems and now he feels more comfortable about trying a new problem in mathematics.

To summarize, writing assignments have been beneficial to all four participants. Just by "writing out the process of solving a problem" or "writing out the steps of solving a problem" has made a big difference. The participants mentioned becoming independent problem solvers and active learners due to doing the weekly writing assignments as revealed from interview data analysis. Here is a list of ways in which writing assignments have improved the participants' attitudes toward mathematics.

- can be used as study guides (independent problem solving)

- could seek assistance faster (active learning)

- learned how to break the entire problem into pieces (independent problem solving)

- able to fully understand what needs to be fixed to get to the solution (active learning)

- $\quad$ helped with retention and recall (active learning)

- $\quad$ provided with an opportunity to keep track of feelings [while doing the math] 


\section{Educational Implications}

After implementing writing assignments in my Elementary Algebra classroom and analyzing the data, I have reason to believe that college students' attitudes toward mathematics have improved. Before this research project, I found myself assuming that college students understood every math problem and were able to seek assistance when they were stuck on problems from the tutors very easily. Through this project, I gained insight into the issues they face in this course and the manner in which I could provide help. I have come to realize that students become independent problem solvers and active learners due to the integration of weekly writing assignments. Moreover, college students develop the skills to figure out their own mistakes, keep a record of their progress and feelings, and thus become more comfortable and confident in solving problems in mathematics as a result of doing weekly writing in mathematics. If the writing assignments were incorporated for more than five weeks, the effects of writing assignments could have led to the emergence of more ways or factors that are responsible for the improvement of attitudes toward mathematics.

By doing this action research project, I have come to realize the potential that writing in mathematics has on college students' attitudes toward mathematics. The feedback from students as gathered from surveys and interviews has provided me the opportunity to see some great results of incorporating constructivist-based ideas in my own mathematics classroom which earlier seemed impossible. I found this experience invaluable and I will continue to include writing and reflection at least for a few weeks, if not the entire semester while teaching mathematics courses in the future.

As I teach the course in the fall 2015 semester, I would incorporate the writing activities and reflection as a part of the course for extra credit to increase participation, which might not be possible otherwise. I believe that students really appreciated the opportunity for corrections and points on the incorrect problems. Based on the results of this study, I hope to make recommendations about the benefits of writing activities to my fellow teachers. Due to the self-paced nature of the course and due to the lesser degree of teacher involvement, many students feel left out and end up failing the class thinking that there is no one to guide them. Most importantly, I would not have learned about John's misconceptions. I am more determined to reach out to such students in a sympathetic way now that I have learned what they might be thinking and what can be done to address the missing teacher/tutor assistance that this course lacks.

\section{References}

Allen, B. R. (1991, July). A study of metacognitive skills as influenced by expressive writing in college introductory algebra classes. 
Unpublished Doctoral Dissertation, Louisiana State University, Baton Rouge.

Bell, E., \& Bell, R. (1985). Writing and mathematical problem solving: Arguments in favor of synthesis, School Science and Mathematics, 85(3), 210-221.

Countryman, J. (1992). Writing to learn mathematics. Heinemann, Portsmouth, NH.

Erlwanger, S. H. (1973). Benny's conception of rules and answers in IPI mathematics. Journal of Children's Mathematical Behavior, 1(2), 726.

Haladyna, T., Shaughnessy, J., \& Shaughnessy, M. (1983). A causal analysis of attitude toward mathematics. Journal for Research in Mathematics Education, 14(1), 19-29.

Hart, L. (1989). Classroom processes, sex of student, and confidence in learning mathematics. Journal for Research in Mathematics Education, 20(3), 242-260.

Hayden, R. (1989). Using writing to improve student learning of statistics. Writing Across the Curriculum, 8, 1-8.

Hirschfeld-Cotton, K. (2008). Mathematical communication, conceptual understanding, and students' attitudes toward mathematics. Action Research Projects. Retrieved from http://scimath.unl.edu/MIM/files/research/CottonK.pdf

Idris, N. (2009). Enhancing students' understanding in calculus through writing. International Electronic Journal of Mathematics Education, 4(1), 36-55.

Jurdak, M., \& Abu Zein, R. (1998). The effect of journal writing on achievement in and attitudes toward mathematics. School Science and Mathematics, 98(8), 412-419.

Ma, X. (2003). Effects of early acceleration of students in mathematics on attitudes toward mathematics and mathematics anxiety. Teachers College Record, 105(3), 438-464.

Ma, X., \& Xu, J. (2004). The causal ordering of mathematics anxiety and mathematics achievement: a longitudinal panel analysis. Journal of Adolescence, 27(2), 165-179.

McLeod, D. B. (1992). Research on affect in mathematics education: A reconceptualization. In D. A. Grouws (Ed.), Handbook of research on mathematics teaching and learning (pp. 575- 596). New York: Macmillian.

National Council of Teachers of Mathematics. (2000). Principles and standards for school mathematics. Reston, VA: Author.

National Institute for Literacy. (2007). What content-area teachers should know about adolescent literacy. Washington, DC: Author. Retrieved from https://lincs.ed.gov/publications/pdf/adolescent_literacy07.pdf 
Patton, M. (2002). Qualitative research and evaluation methods. Thousand Oaks, CA: Sage.

Pugalee, D. K. (1997). Connecting writing to the mathematics curriculum. Mathematics Teacher, 90(4), 308-310.

Simon, M., Tzur, R., Heinz, K., \& Kinzel, M. (2004). Explicating a mechanism for conceptual learning: Elaborating the construct of reflective abstraction. Journal for Research in Mathematics Education, 35(5), 305-329.

Zan, R., \& Martino, P.D. (2007). Attitudes towards mathematics: Overcoming positive/negative dichotomy. The Montana Mathematics Enthusiasts Monograph 3, pp 157-168. The Montana Council of Teachers of Mathematics.

Urquhart, V. (2009). Using writing in mathematics to deepen student learning. Denver, CO: Mid-continent Research for Education and Learning. Retrieved from http://www.mcrel.org/

\section{Appendix A}

\section{Pre/Post Survey}

\section{Attitudes toward Mathematics Survey (MAT)}

For each of the following statement, please circle the one response that best fits your view.

Strongly Disagree $\quad$ Disagree $\quad$ Agree $\quad$ Strongly Agree

1. I like Mathematics

2. I understand Mathematics.

3. I find learning Mathematics easy.

4. I am motivated in Mathematics.

5. I feel comfortable about trying a new problem in Mathematics.

6. I feel confident about trying a new problem in Mathematics.

7. I am able to interact with my class mates with confidence about mathematics.

8. I find class activities helpful in preparing me for the Mathematics test.

9. I understand Mathematics concept easily.

10. I understand Mathematical concepts promptly (quickly).

11. I like spending time on Mathematics.

12. I can get good grades in Mathematics.

13. Do you think your attitude toward mathematics is positive or negative? Circle one

NEGATIVE

POSITIVE

14. Describe your feelings when you are watching MATH 0920 videos?

15. Describe your feelings while solving MATH 0920 problems inside and outside classroom.

Please fill in the following information:

Name:

Major field of study: 


\section{Appendix B}

\section{Interview Guide (Estimated Time: 30 mins) Introduction Script:}

Thank you for taking the time to participate in my research. The purpose of this research is to qualitatively explore Laramie County Community College (LCCC) Elementary Algebra students' attitudes toward mathematics due to weekly writing assignments. During this time, I will ask you to share your experiences and attitudes about solving problems assigned on weekly assignments. Please understand that participating in this research will not impact your course grade one way or the other. It is ok if you don't know the answers to the questions. I ask that you simply do your best. If at any time you want to stop this interview, I will do so immediately. As mentioned earlier, I will address you with your assigned pseudonym to maintain confidentiality. I will audio-record the entire session. Also, please do not share these questions with other students in order to make responses valid. Do you have any questions? Are you ready to begin?

\section{Interview Questions:}

1. Tell me if you feel that the incorporation of weekly writing assignments have changed your attitudes toward mathematics. If so, how?

Clarification: Did you enjoy or were they annoying? [To seek more clarification about item \#11 and items \#8 of MAT (especially if the post-survey response is different from the pre-survey response)].

Follow up: 1) Discuss (probe) about the change (in attitudes) from pos-neg or neg-pos, if noticed from survey.

2. Tell me if you feel confident about trying a new problem in this course.

Clarification: [To seek more clarification about item\#6 of MAT (especially if the post-survey response is different from the pre-survey response)].

Follow up: 1) Do you feel that by reflecting on each problem it helped you to get closer to your main goal or solution and when you see similar problem on the exam or on any module section?

3. Tell me how confident you feel about solving problem(s) (similar to the problems that you did on assignments) on the final. [To pull up a problem from the writing assignment and see what the participant has to say]

Clarification: On a scale of 0-10, tell me what number would you pick? [To seek more clarification about item\#12 of MAT (especially if the post-survey response is different from the pre-survey response)].

4. Do you plan to continue to reflect on a math problem in your future math coursework?

5. Would you recommend that writing assignments involving reflection become a part of this course to future students? 


\section{Appendix C}

\section{Examples of Writing Assignments}
Writing Assignment\#4
SARA
Due: $04 / 3 / 2015$

1) Find an equation of the line with the given slope that passes through the given point. Express your answer in the form $\mathrm{Ax}+\mathrm{By}=\mathrm{C}$.

$\mathrm{m}=7 / 4$, point $=(8,-6)$

(Module $9 \sec 3.5$ )

2) Find an equation of the line passing through the pair of points $(2,7)$ and $(7,2)$. Express your answer in the slope intercept form $(y=m x+b)$. (Module $9 \mathrm{sec}$ $3.5)$

Writing Assignment\#5

JOHN

Due: 04/10/2015

1) Solve for $y$ :

$0.16(\mathrm{y}-8)-0.18 \mathrm{y}=0.14 \mathrm{y}-0.03(40)$

(Module $6 \sec 2.3$ )

2) Solve for $\mathrm{x}$ :

(Module 6 sec 2.3)

$\frac{2}{9} x-\frac{1}{3}=-1$

3) Solve for $\mathrm{x}$ :

(Module $6 \sec 2.3$ )

$\frac{5}{3}(x+4)=2 x-3$

\section{Authors:}

Soofia Malik

University of Northwestern Ohio, U.S.A

Email: malik@mtu.edu 